\title{
COMPARISON BETWEEN THE EFFECT OF CONVENTIONAL REMOVABLE PARTIAL DENTURES AND TELESCOPIC REMOVABLE PARTIAL DENTURES ON POCKET DEPTHS AND ALVEOLAR BONE HEIGHT OF ABUTMENT TEETH
}

\author{
Ahmed Fayyad * and Nagla Nassouhy*
}

\begin{abstract}
Objective: this study was conducted to compare the effect of the conventional removable partial dentures (RPDs) and telescopic partial dentures on pocket depths and alveolar bone height of abutment teeth after a follow-up period of one year.

Materials and Methods: twenty eight patients with mandibular bilateral free-end saddle were selected for this study, with canines and first premolars as last standing abutments on both sides and an opposing maxillary dentulous arch. They were randomly divided into two groups, group I receiving a conventional RPD, and group II receiving a telescopic partial denture. CAD/CAM technology was used for the fabrication of Polymethylmethacrylate patterns for both copings and frameworks for the two groups followed by casting in the conventional manner. Radiographic bone height measurements and pocket depth measurements were performed for the two groups at denture delivery and after one year.
\end{abstract}

Results: there was no significant difference in percentage bone loss and pocket depth between the two groups after one year. However, only group II showed a significant increase in pocket depth after one year of follow-up. There was also an increase in bone loss in both groups after one year but it was not significant.

Conclusion: Minor changes in pocket depths and alveolar bone height were observed in both groups. However, the telescopic partial denture showed signs of gingival inflammation and increased pocket depths, while the conventional removable partial denture showed more favorable results.

\section{INTRODUCTION}

Removable partial dentures (RPDs) remain a reliable treatment option for many partially edentulous patients, especially with older patients or those with anatomical, financial or systematic conditions that limit the use of implant treatment ${ }^{(1-2)}$. RPDs provide a fast, conservative and cost effective treatment option for both dentist and patient, with

*Lecturer of Prosthodontics, Cairo University 
reliable long-term outcomes for up to 10 years ${ }^{(3-4)}$. However, their use could be associated with several problems. Complaints regarding esthetic outcomes, masticatory performance and patient satisfaction are common with partial denture patients ${ }^{(5-7)}$. In addition, RPDs - especially distal extension base partial dentures - are known for their negative impact on the remaining oral structures, mainly abutment teeth and the residual ridge ${ }^{(8-11)}$.

Studies have shown that RPDs might contribute to periodontal problems in abutment teeth ${ }^{(3,12-13)}$. Amaral et al. reported that direct and indirect retainers increased plaque accumulation, gingival inflammation and probing depths on abutment teeth when compared to non-abutment teeth after one year follow-up ${ }^{(1)}$. Higher caries incidence was also reported with clasp-retained RPDs ${ }^{(14-16)}$. One study by Wagner and Kern showed that caries occurred in abutment teeth twice as frequently as in nonabutment teeth after one year of clinical use ${ }^{(3)}$. In another study that reported results after 5 years of use, caries incidence was six times higher in RPDs than in fixed restorations ${ }^{(4)}$. These problems could be attributed to the effect of clasps and other denture components on biofilm formation ${ }^{(3-4)}$. Poor hygiene habits and lack of frequent recall visits were found to aggravate these dental and periodontal problems in RPD wearers over prolonged periods of use $\mathrm{e}^{(3,9)}$.

The importance of regular recall visits and hygiene measurements have been emphasized in the literature as they had a significant effect on preserving the periodontal and dental health of the remaining teeth $^{(3)}$. Some clinical studies demonstrated that with a proper recall and maintenance program as well as hygiene motivation and persistence, RPDs might not have any damaging effects on the periodontium of abutment teeth. In a 10-year longitudinal study by Bergman et al. where patient cooperation was high and maintenance recall visits were consistent, there was no significant deterioration in the periodontal and dental conditions of the abutment teeth ${ }^{(I)}$.
Isidor and Budtz-Jorgenson reported no change in probing depths and a minor amount of bone loss after 5 years of use ${ }^{(2)}$. Kapur et al. emphasized that proper design and construction of RPDs in addition to regular maintenance and oral prophylaxis offer satisfactory treatment outcomes for a follow-up period of 5 years ${ }^{(6)}$.

Telescopic removable partial dentures have been successfully used for the treatment of partially edentulous patients ${ }^{(17-18)}$. They consist of a primary coping, which is cemented to the abutment teeth, and a secondary coping which lies within the removable partial denture ${ }^{(19)}$. Telescopic partial dentures achieve retention through friction between the walls of the primary coping and the secondary coping. Telescopic copings could be parallel-walled or conical with a well-defined degree of taper. Retention is achieved through friction between the parallel walls, whereas conical crowns exhibit friction when completely seated ${ }^{(19-21)}$.

Telescopic partial dentures were found to enhance esthetics by completely eliminating clasps on abutment teeth. They also provide complete tooth coverage which offers protection against caries, thereby decreasing its incidence ${ }^{(3)}$. Furthermore, force distribution is more favorable with telescopic partial dentures as forces are transferred along the long axis of abutment teeth, thereby stabilizing the prosthesis against vertical and horizontal forces ${ }^{(22-23)}$.

On the other hand, telescopic partial dentures are technically more challenging to fabricate, requiring more laboratory and clinical skills than the simpler conventional clasp-retained RPDs, thereby increasing the cost of treatment to the patient. They also required more maintenance procedures than conventional RPDs ${ }^{(24)}$. Loss of cementation of the primary coping followed by veneer chipping of the secondary coping are the most common complications observed with telescopic partial dentures ${ }^{(25-26)}$. Furthermore, oral hygiene measures 
may sometimes be compromised by over contouring of the telescopic copings, resulting in gingival inflammation and increased pocket depths ${ }^{(24)}$.

In conclusion, conventional RPDs might be simpler, more conservative and less costly than telescopic RPDs. However, their effect on the health of periodontium of abutment teeth might be more detrimental. This in-vivo study was conducted to compare the effects of clasp-retained RPDs and telescopic RPDs on alveolar bone height and pocket depths of abutment teeth after a follow-up period of one year.

\section{MATERIALS AND METHODS}

This study was designed to be a parallel randomized clinical trial. Twenty eight partially edentulous patients were selected after recording their medical and dental histories as well as performing proper intra and extra-oral examination and radiographic assessment. All the included patients had mandibular Kennedy class I arches with the first premolar as a last standing abutments bilaterally and completely dentulous upper arches. Patients were divided into two equal groups; patients of Group I received a mandibular distal extension removable partial denture retained by conventional clasps, while patients of Group II received a mandibular distal extension removable partial denture retained by telescopic crowns. After proper diagnosis, all patients that were selected to be included in the study were requested to sign an informed consent.

Maxillary and mandibular primary impressions* were made in a properly selected stock tray and poured in dental stone ${ }^{* *}$ to obtain diagnostic casts. Mounting of the diagnostic casts was performed using tentative jaw relation record to evaluate the occlusion, presence of super eruption or tilted teeth and to verify the available inter-arch space in order to perform any adjustments required before starting the prosthetic phase.

\section{Group I patients:}

Patients of group I received mandibular distal extension removable partial denture retained by conventional clasps. The framework design included a lingual bar as a major connector, Akers clasps on mandibular first premolars as retainers and auxiliary cingulum rests on the canines. After mouth preparation and secondary impression, the obtained master cast was scanned and CAD/CAM technology was used to design and mill the pattern for the framework in polymethylmethacrylate (PMMA). The framework was then invested and cast in cobalt chromium alloy. Partial denture construction was then continued in the conventional manner (Figure 1).

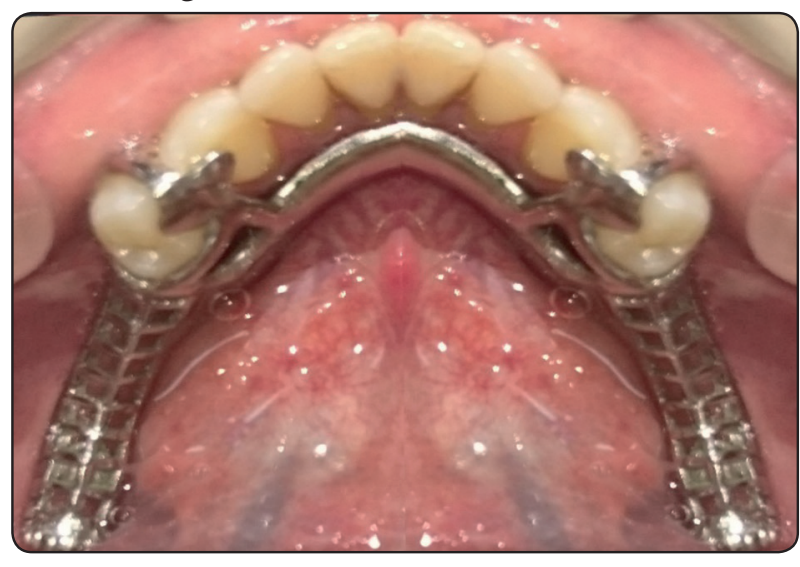

Fig. (1) The metal framework of conventional removable partial denture intraorally.

\section{Group II Patients}

After proper local anesthesia was administrated, preparation of the supporting abutments (mandibular canine and first premolars) on either side was done by using a tapered stone with round end creating a deep chamfer finishing line with sufficient occlusal

\footnotetext{
* (Cavex, CA-37, superior pink, Holland)

** (Moldano, Bayer Co. Leverkusen)
} 
and axial reduction to receive the primary and secondary copings. Gingival retraction was done then single step impression was made using addition silicon in a special tray.

By using CAD/CAM technology, the obtained cast was scanned, and the primary copings were designed to achieve 2 degree of tapering walls and $0.3 \mathrm{~mm}$ thickness, and a polymethylmethacrylate (PMMA) burnable copings was milled by CAD/ CAM milling machine.

The PMMA pattern was invested, burnt out and finally casted into cobalt-chromium alloy. The primary copings were then finished and polished then tried in the patient's mouth and checked for complete seating, proper fit and adaptation to the finishing line of the prepared abutment. The primary copings were then finally cemented using glass ionomer cement and left to finally set for 24 hours, (Figure 2).

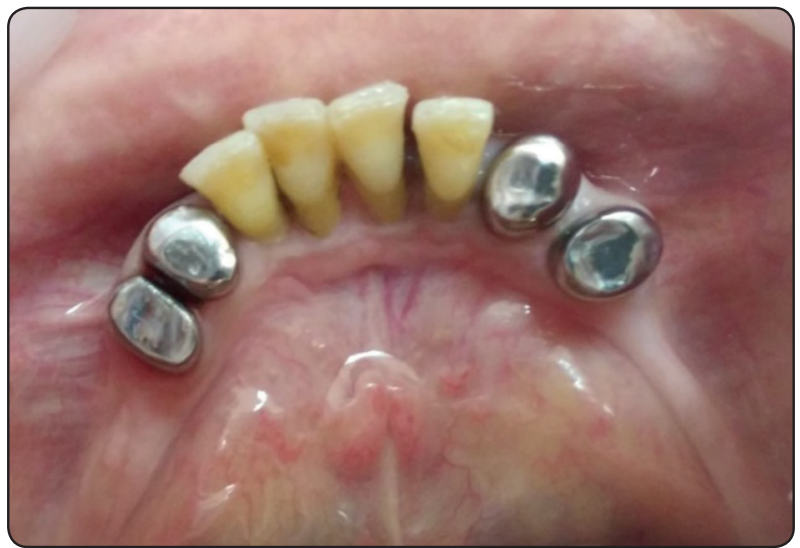

Fig. (2) The primary copings cemented intraorally.

The final impression of the ridge and the primary copings were made using rubber base impression material in a special tray which was constructed on a primary cast with $2 \mathrm{~mm}$ spacer. After setting, the impression was removed and poured into extra-hard dental stone to obtain a master cast. By using CAD/
CAM technology*, the obtained cast was scanned, surveyed, designed, and a polymethylmethacrylate (PMMA) burnable template design was milled by $\mathrm{CAD} / \mathrm{CAM}$ milling machine (Figure 3).

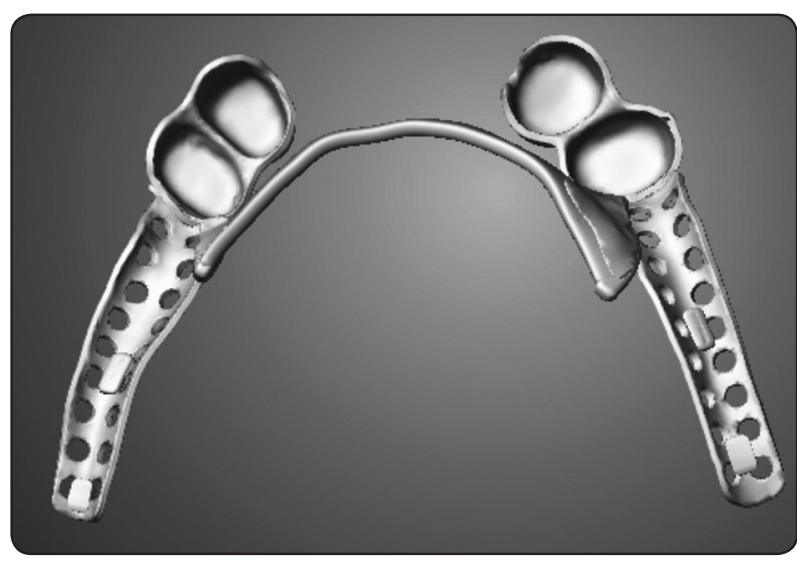

Fig. (3) The computer aided design of the telescopic framework

The (PMMA) burnable template was sprued, invested, and casted into base metal alloy. The finished casting was tried in the patients' mouth and checked for complete seating, stability and adequate retention between the primary and secondary copings. Mounting of the casts was made in centric relation on a semi adjustable articulator. The secondary copings were covered with porcelain layer after shade matching to enhance esthetic of the prosthesis. Cross linked acrylic resin teeth were then set in the edentulous areas and the framework was re-tried in the patient mouth to check patient acceptance, esthetic and occlusion. The trial denture was flasked, packed and processed. Finally, the finished denture was delivered to the patient and any necessary adjustments were made.

Patients were given thorough oral hygiene instructions and were recalled frequently for inspection and hygiene prophylaxis and maintenance during the follow-up period. Clinical and radiographic 
evaluations were done at the time of denture delivery and after the one year follow-up period.

\section{Radiographic Evaluation}

An image plate was mounted on a radiographic stent especially constructed for each patient to take a standardized periapical radiograph for the abutments using paralleling cone technique. The Digora $^{1}$ software was used to evaluate the marginal bone loss around the abutments in both groups.

The digital images were analyzed to evaluate the marginal bone level mesial and distal to the canine and first mandibular premolars bilaterally in both groups (Figure 4).

Measuring procedures was done as follows; First line was drawn tangential to tooth apex (line "1") using the Digora software. Then two other lines (line "2" and line "3"), one on the mesial and the other on the distal of the tooth were drawn to extend from the highest level of the alveolar crest to the horizontal line (line "1"). This procedure was performed for the canine and first premolar bilaterally in both groups.

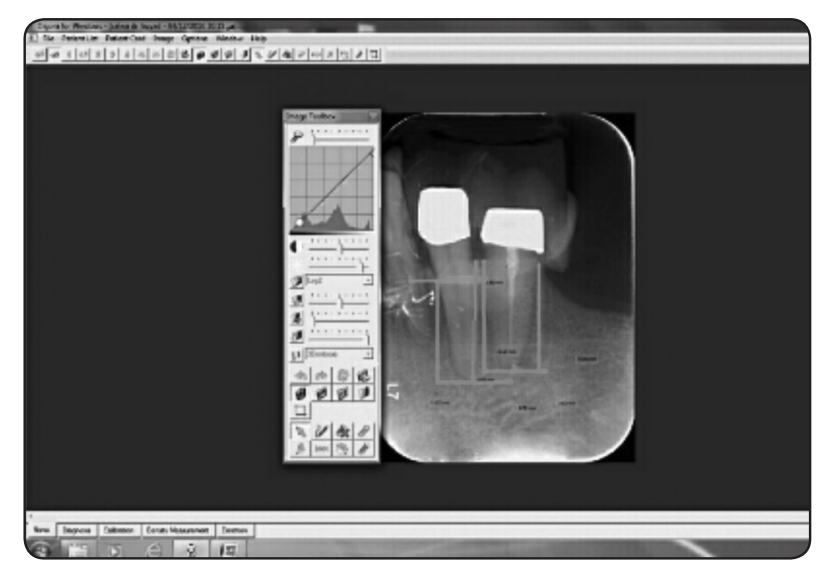

Fig. (4) A direct digital radiograph of the canine and the first premolar demonstrating the bone height measurements performed by the Digora software

\section{Clinical Evaluation}

Pocket depths were measured using a periodontal probe. Pocket depths were measured from a constant point on top of the abutment teeth in the two groups till the depth of the gingival crevice. Measurements were made on the mid-buccal and mid-lingual surfaces of the abutment teeth.

\section{RESULTS}

The mean and standard deviation values were calculated for each group. Data were explored for normality using Kolmogorov-Smirnov and Shapiro-Wilk tests and showed parametric (normal) distribution.Paired-samples t-test was used to compare between dependent samples while Independent sample-t test was used to compare between independent samples. The significance level was set at $\mathrm{P} \leq 0.05$. Statistical analysis was performed with IBM ${ }^{\circledR}$ SPSS ${ }^{\circledR}$ Statistics Version 20 for Windows.

\section{Bone Height results:}

There was no statistically significant difference in mean value of bone height change between the beginning of the study and after one year in both groups $(\mathrm{p}=0.871)$.

\section{Relation between the two groups after one year}

There was no statistically significant difference in mean of bone height change between Group I and Group II where $(p=0.395)$. The highest mean value of bone height change was found in Group II (13.28 \pm 1.42 ) while the least mean value of bone height change was found in Group I (12.90 \pm 1.05$)$.

There was no statistically significant difference in mean value of percentage of change in bone height between Group I and Group II where $\mathrm{p}=0.858$. The highest mean value of percentage of change was found in Group II $(2.04 \%)$ while the least mean value of percentage of change $(1.96 \%)$ was found in Group I (Table 1, figure 5). 
TABLE (1) The mean, standard deviation (SD) values of percentage of change of bone height in both groups.

\begin{tabular}{|c|c|}
\hline Variables & Percentage of change of bone height \\
\hline Group I & $1.96 \%^{\mathrm{a}}$ \\
\hline Group II & $2.04 \%^{\mathrm{a}}$ \\
\hline P-value & $\mathbf{0 . 8 5 8 n \mathrm { n }}$ \\
\hline
\end{tabular}

Mean with different letters in the same column indicate statistically significance difference *; significant $(p<0.05)$ ns; non-significant ( $p>0.05)$

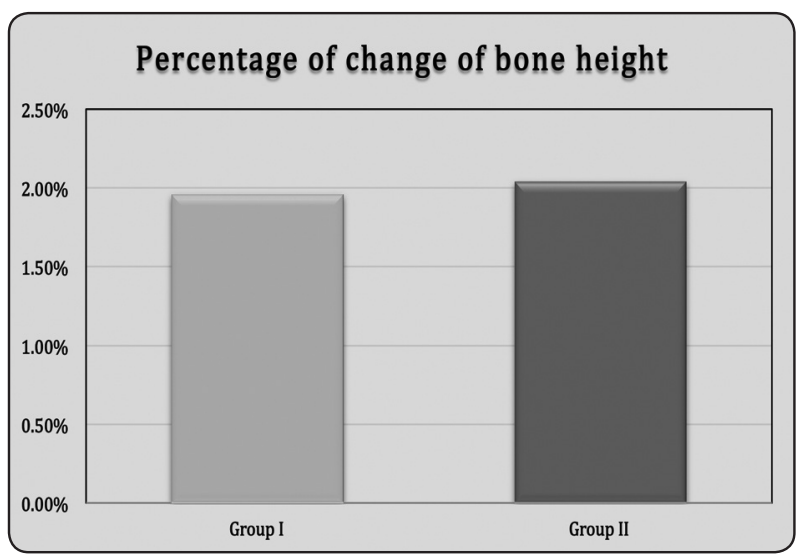

Fig. (5) Bar chart representing means of percentage of change in bone height of both groups

\section{II) Pocket depth results:}

\section{For Group I:}

There was no statistically significant difference in mean value of pocket depths between the beginning of the study and After year where $(\mathrm{p}=0.050)$.

\section{For Group II:}

There was a statistically significant difference in mean value of pocket depth between the beginning of the study and After year where $(p=0.004)$.

\section{Relation between the two groups after year:}

There was no statistically significant difference in mean value of pocket depth between Group I and Group II where $(p=0.212)$. The highest mean value of pocket depth was found in Group II $(10.52 \pm 0.75)$, while the least mean value of pocket depth $(9.20 \pm 0.25)$ was found in Group I (Table 2, figure 6).

TABLE (2): The mean, standard deviation (SD) values of pocket depth of both groups.

\begin{tabular}{|c|c|c|c|}
\hline \multirow{2}{*}{ Variables } & Base line & After year & \multirow{2}{*}{ P-value } \\
\cline { 2 - 3 } & Mean \pm SD & Mean \pm SD & \\
\hline Group I & $8.62 \pm 0.09^{\mathrm{A}}$ & $9.20 \pm 0.25^{\text {a }}$ & \multirow{2}{*}{$\mathbf{0 . 0 5 0 n s}$} \\
\hline Group II & $7.02 \pm 0.17^{\mathrm{A}}$ & $10.52 \pm 0.75^{\text {а в }}$ & \multirow{2}{*}{$\mathbf{0 . 0 0 4}$} \\
\hline P-value & \multicolumn{2}{|c|}{$\mathbf{0 . 2 1 2 n s}$} & \\
\hline
\end{tabular}

Means with different small letters in the same column indicate statistically significance difference, means with different capital letters in the same row indicate statistically significance difference. $*$; significant $(p<0.05)$ $n s ;$ non-significant (p>0.05)

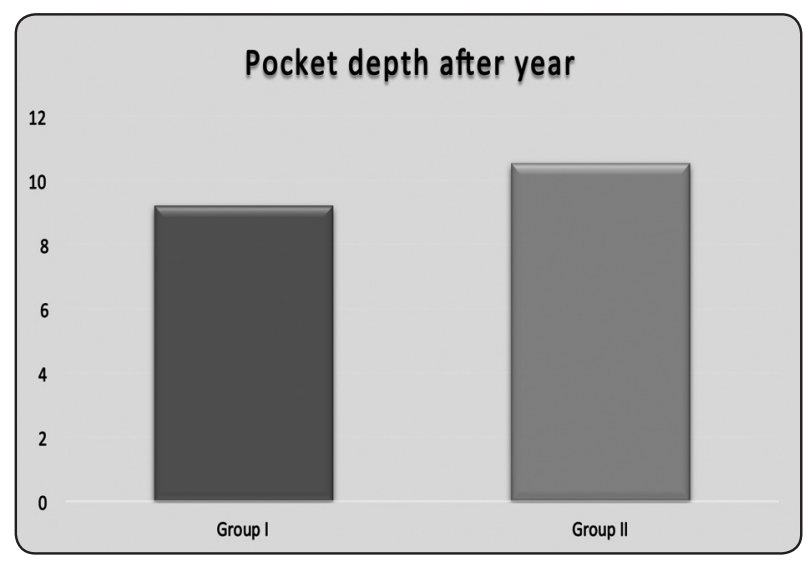

Fig. (6) Bar chart representing means of pocket depth in both groups 


\section{DISCUSSION}

As stated by Devan 1952 "Preservation of what is remaining rather than restoration of what is missing" is always our goal in prosthetic dentistry ${ }^{(27)}$. The aim of this study was to evaluate the soft and hard tissue conditions around the main abutments supporting partial denture restoring bilateral free end saddle cases. These cases are challenging due to the absence of posterior tooth support which leads to torque on the main abutments.

Generally speaking, the simpler the design of the prosthesis is, the better the results. The results of this study demonstrated favorable reaction of the natural abutments in case of conventional partial denture since all the stresses transmitted to them are controlled and kept to within the physiologic tolerance of the supporting structures.

Nevertheless, the effect of denture and oral hygiene could never be denied. Patients in this study followed a regular hygiene maintenance program. This could be performed with ease in the conventional partial denture group. However, in the telescopic group the space between the two telescopic primary copings was narrow which made oral hygiene procedures more difficult. Besides, this narrow space did not give the chance for physiologic stimulation, a thing which affected the health of that important area of the gingiva as detected clinically in this study by increased pocket depth and gingival inflammation.

Although there was an increase in bone loss in both groups, it was not statistically significant. This was an expected result as all the biomechanical principals were strictly followed in both groups, especially with a follow-up period of only one year. This comes in accordance with studies by Chandler and Brudvik ${ }^{(28)}$ as well as Isidor and BudtzJorgensen $^{(2)}$ who reported no changes in probing depths and only minor amounts of bone loss with RPDs. However, in the telescopic group, bone loss was more than the conventional partial denture group, but this difference was not statistically significant. In addition, the clinical evaluation showed that the soft tissue area surrounding the primary copings in the telescopic group was inflamed and edematous which was not the case in group II. The inflammation in that area may spread deeply in the investing tooth structure and may be the starting point for the periodontal disease and its sequelae. Therefore, it can $b$ suggested that if this study was extended for a longer period, the results might have been different.

\section{CONCLUSION}

The results of this study showed that conventional removable partial dentures as well as telescopic partial dentures are reliable treatment options for free end saddle cases. Minor changes in pocket depths and alveolar bone height were observed in both groups. However, the telescopic partial denture showed signs of gingival inflammation and increased pocket depths, while the removable partial denture showed more favorable results. This study was only conducted for one year; longer follow-up periods are required to evaluate the effects of these results on alveolar bone height.

\section{REFERENCES}

1. Bergman, B., A. Hugoson, and C.O. Olsson, Caries, periodontal and prosthetic findings in patients with removable partial dentures: a ten-year longitudinal study. J Prosthet Dent, 1982. 48(5): p. 506-14.

2. Isidor, F. and E. Budtz-Jorgensen, Periodontal conditions following treatment with distally extending cantilever bridges or removable partial dentures in elderly patients. A 5-year study. J Periodontol, 1990. 61(1): p. 21-6.

3. Wagner, B. and M. Kern, Clinical evaluation of removable partial dentures 10 years after insertion: success rates, hygienic problems, and technical failures. Clin Oral Investig, 2000. 4(2): p. 74-80.

4. Budtz-Jorgensen, E. and F. Isidor, A 5-year longitudinal study of cantilevered fixed partial dentures compared with removable partial dentures in a geriatric population. J Prosthet Dent, 1990. 64(1): p. 42-7. 
5. Kay, E.J., Patients' needs--more than meets the eye. $\mathrm{Br}$ Dent J, 1993. 174(6): p. 212-4.

6. Kapur, K.K., R. Deupree, R.J. Dent, et al., A randomized clinical trial of two basic removable partial denture designs. Part I: Comparisons of five-year success rates and periodontal health. J Prosthet Dent, 1994. 72(3): p. 268-82.

7. Kapur, K.K., N.R. Garrett, R.J. Dent, et al., A randomized clinical trial of two basic removable partial denture designs. Part II: Comparisons of masticatory scores. J Prosthet Dent, 1997. 78(1): p. 15-21.

8. Arce-Tumbay, J., A. Sanchez-Ayala, B.S. Sotto-Maior, et al., Mastication in subjects with extremely shortened dental arches rehabilitated with removable partial dentures. Int J Prosthodont, 2011.24(6): p. 517-9.

9. Kern, M. and B. Wagner, Periodontal findings in patients 10 years after insertion of removable partial dentures. J Oral Rehabil, 2001. 28(11): p. 991-7.

10. Wostmann, B., E. Budtz-Jorgensen, N. Jepson, et al., Indications for removable partial dentures: a literature review. Int J Prosthodont, 2005. 18(2): p. 139-45.

11. do Amaral, B.A., A.O. Barreto, E. Gomes Seabra, et al., A clinical follow-up study of the periodontal conditions of RPD abutment and non-abutment teeth. J Oral Rehabil, 2010. 37(7): p. 545-52.

12. Tuominen, R., K. Ranta, and I. Paunio, Wearing of removable partial dentures in relation to periodontal pockets. J Oral Rehabil, 1989. 16(2): p. 119-26.

13. Yusof, Z. and Z. Isa, Periodontal status of teeth in contact with denture in removable partial denture wearers. J Oral Rehabil, 1994. 21(1): p. 77-86.

14. Wright, P.S. and P.H. Hellyer, Gingival recession related to removable partial dentures in older patients. J Prosthet Dent, 1995. 74(6): p. 602-7.

15. Nevalainen, M.J., T.O. Narhi, and A. Ainamo, A 5-year follow-up study on the prosthetic rehabilitation of the elderly in Helsinki, Finland. J Oral Rehabil, 2004. 31(7): p. 647-52.

16. Wright, P.S., P.H. Hellyer, D. Beighton, et al., Relationship of removable partial denture use to root caries in an older population. Int J Prosthodont, 1992. 5(1): p. 39-46.
17. Koller, B., W. Att, and J.R. Strub, Survival rates of teeth, implants, and double crown-retained removable dental prostheses: a systematic literature review. Int J Prosthodont, 2011. 24(2): p. 109-17.

18. Schwindling, F.S., B. Dittmann, and P. Rammelsberg, Double-crown-retained removable dental prostheses: a retrospective study of survival and complications. J Prosthet Dent, 2014. 112(3): p. 488-93.

19. Isaacson, G.O., Telescope crown retainers for removable partial dentures. J Prosthet Dent, 1969. 22(4): p. 436-48.

20. The glossary of prosthodontic terms. J Prosthet Dent, 2005. 94(1): p. 10-92.

21. Hulten, J., B. Tillstrom, and K. Nilner, Long term clinical evaluation of conical crown retained dentures. Swed Dent J, 1993. 17(6): p. 225-34.

22. Bergman, B., A. Ericson, and M. Molin, Long-term clinical results after treatment with conical crown-retained dentures. Int J Prosthodont, 1996. 9(6): p. 533-8.

23. Wenz, H.J., K. Hertrampf, and K.M. Lehmann, Clinical longevity of removable partial dentures retained by telescopic crowns: outcome of the double crown with clearance fit. Int J Prosthodont, 2001. 14(3): p. 207-13.

24. Verma, R., T. Joda, U. Bragger, et al., A systematic review of the clinical performance of tooth-retained and implantretained double crown prostheses with a follow-up of $>/=$ 3 years. J Prosthodont, 2013. 22(1): p. 2-12.

25. Hofmann, E., M. Behr, and G. Handel, Frequency and costs of technical failures of clasp- and double crownretained removable partial dentures. Clin Oral Investig, 2002. 6(2): p. 104-8.

26. Behr, M., E. Hofmann, M. Rosentritt, et al., Technical failure rates of double crown-retained removable partial dentures. Clin Oral Investig, 2000. 4(2): p. 87-90.

27. Devan, M.M., The nature of the partial denture foundation: Suggestions for its preservation. J Prosthet Dent, 1952. 2(2): p. $210-218$.

28. Chandler, J.A. and J.S. Brudvik, Clinical evaluation of patients eight to nine years after placement of removable partial dentures. J Prosthet Dent, 1984. 51(6): p. 736-43. 